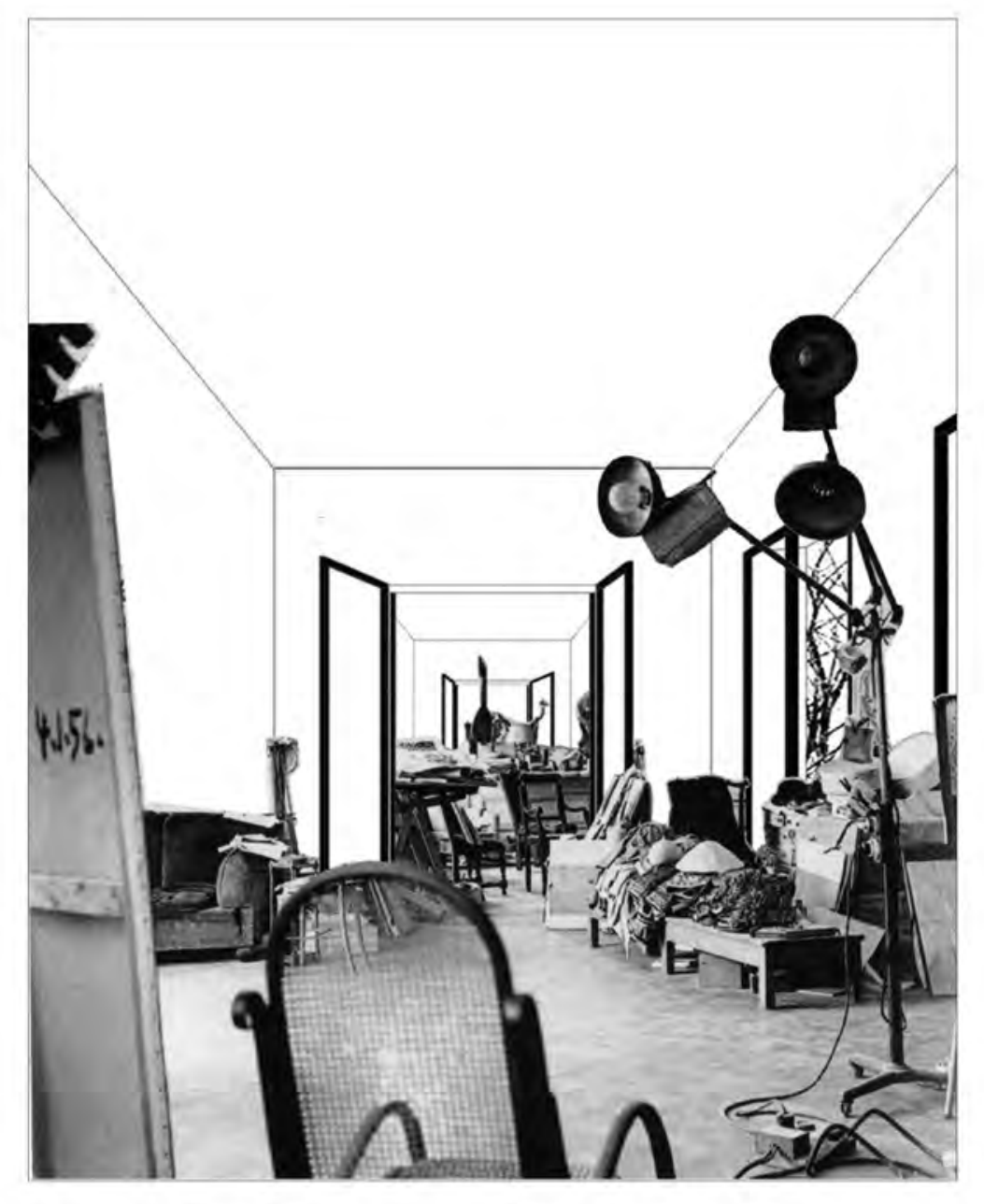

Kersten Geers | Profesor, Accademia di Architettura di Mendrisio.

Arquitecto, Universiteit Gent y Escuela Técnica Superior de Arquitectura de Madrid. Hasta 2001 colaboró en Maxwan Architects; entre 2001 y 2005 lo hizo en el estudio de Neutelings Riedijk. Es autor de numerosos ensayos publicados en revistas de arquitectura internacional. Ha sido docente en Universiteit Gent, Technische Universiteit Delft, Berlage Institute y Columbia University. David van Severen | Profesor, Ecole Nationale Supérieure d'Architecture de Versailles. Arquitecto, Universiteit Gent y Escuela Técnica Superior de Arquitectura de Madrid. Hasta 2004 colaboró alternadamente en los estudios de Stéphane Beel, Xaveer De Geyter y Atelier Maarten Van Severen. Ha sido docente en Amsterdamse Hogeschool voor de Kunsten, Technische Universiteit Delft, ArtEZ Hogeschool voor de Kunsten, Berlage Institute y Accademia di Architettura di Mendrisio.
A partir de una colección de habitaciones idénticas en planta y topológicamente equivalentes, tres imágenes dan cuenta de la crítica relación entre el espacio y los objetos contenidos en él, y de los matices de habitabilidad posibles en un campo neutro.

Palabras clave: Arquitectura - Bélgica, Ordos, visualizaciones, serie.

A collection of identical and topologically equivalent rooms is the origin of three images that show the critical relationship between space and contained objects, and the diverse possibilities that a neutra field offers to dwelling.

Keywords: Architecture - Belgium, Ordos, visualizations, series.
Bibliografía sugerida

BIERIG, Aleksander. "Places of Exception”. Log No 19

Anyone Corporation, Nueva York, 2010.

GeERS, Kersten y David VAN SEVEREN. "One text and eight projects". Perspecta № 44. Yale School of Architecture, New Haven, 2011.

GEERS, Kersten y David VAN SEVEREN. "Bridge for the Handelsbeurs Concert Hall”. $A+U N^{\circ} 475$ Architecture in Belgium and the Netherlands. $\mathrm{A}+\mathrm{U}$ Publishing Co., Ltd., Tokio, abril de 2010. KüNG, Moritz (ed.). Seven Rooms. deSingel - Hatje Cantz, Ostfildern, 2009.

PEZO, Mauricio y Sofía VON ELLRICHSHAUSEN (curadores). META. Diez pabellones para Chile.

Ediciones ARQ, Santiago, 2011

Una selección de planimetrías de 25 habitaciones está disponible para los suscriptores ARQ en edicionesarq.cl

\title{
IMÁGENES PARA 25 HABITACIONES OFFICE KGDVS
}



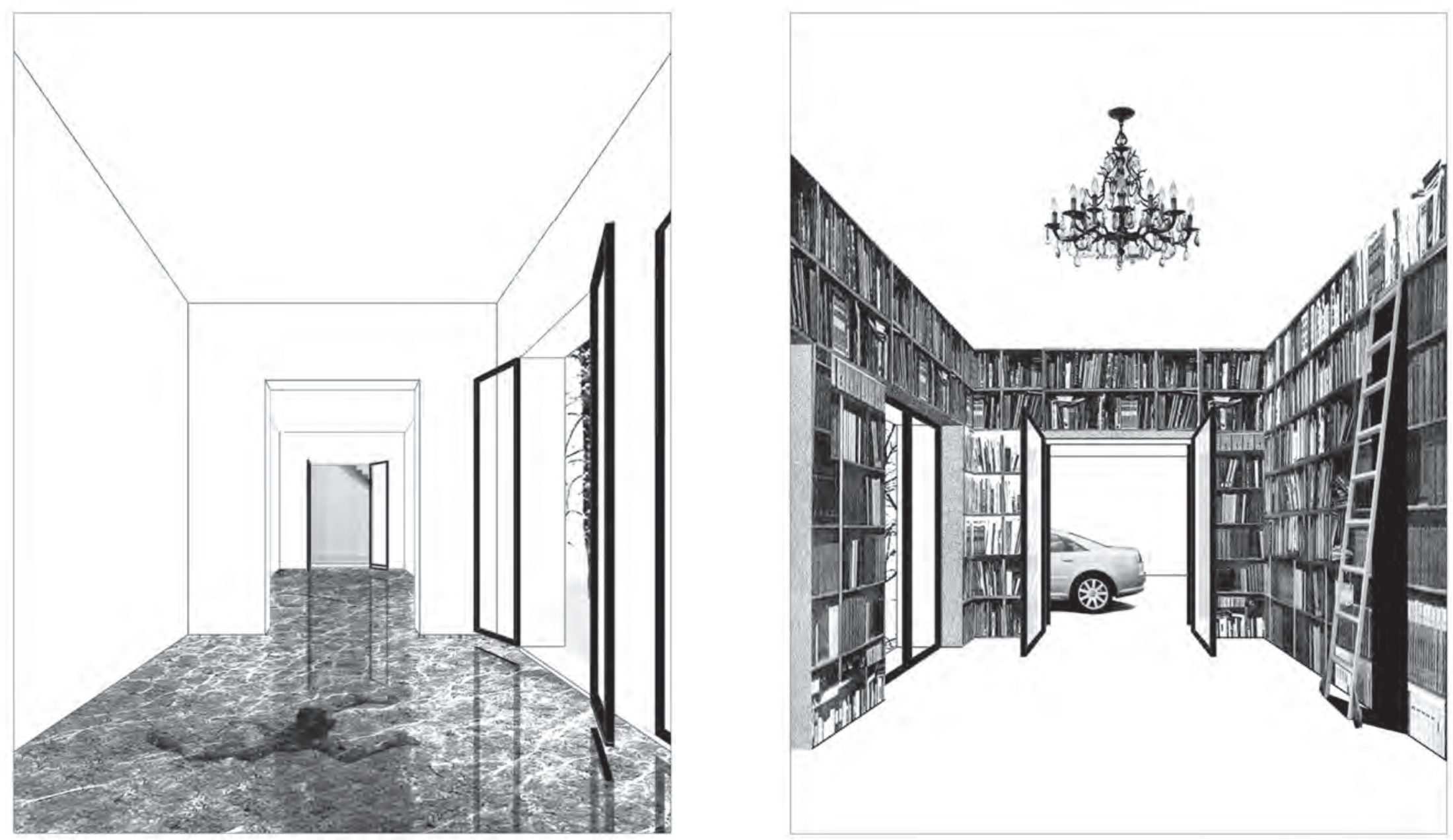

El diseño de esta casa de $1.000 \mathrm{~m}^{2}$ se redujo a un único elemento: una habitación. Un espacio rectangular con cuatro vanos y ninguna función predeterminada. Repetidas 24 veces, estas habitaciones idénticas en planta se organizan en tres niveles para conformar el perímetro de un patio central. Su carácter individual es provisto apenas por ligeras diferencias en las alturas de piso a cielo y por su posición relativa dentro de la casa.

Gran parte de la construcción se proyectó enterrada en el suelo natural. Desde el barrio, apenas puede verse asomado el primero de los tres pisos de la casa, tal como si fuese la punta de un iceberg. El patio central, tratado como un jardín interior excavado, es su espacio al aire libre por excelencia y contribuye a templar las extremas condiciones climáticas del lugar. Todas las habitaciones se abren a este jardín protegido.

Dos sistemas de escaleras, dispuestos cada uno en medio de un recinto a modo de una pieza de mobiliario, permiten la conexión entre los diferentes niveles. El lujo de esta casa no radica en la construcción, sino más bien en la abundancia de espacios. Un misterioso vigésimo quinto recinto sobre el techo -destinado al servicio- se constituye en la única habitación con vistas al exterior: el puesto de un vigía parapetado sobre un grueso muro. ARQ

25 HABITACIONES | Proyecto de OFFICE Kersten Geers David van Severen. Ordos, China, 2008. I Superficie proyectada: $1.000 \mathrm{~m}^{2}$. I Mandantes: Ordos 100; Ai Wei-Wei, Jacques Herzog, Pierre de Meuron. | Imágenes: Office KGDVS. 